
\title{
25 Research Square \\ The Trends and Efficacy of Surgery in the Treatment of Hepatocellular Carcinoma
}

\section{Lei Chen}

Wuhan Union Hospital https://orcid.org/0000-0003-0018-9993

\section{Shi Chen}

wuhan union hospital

\section{Tao Sun}

wuhan union hospital

\section{Fan Yang \\ wuhan union hospital}

Chuansheng Zheng ( $\square$ hqzcsxh@sina.com )

https://orcid.org/0000-0002-2435-1417

\section{Research article}

Keywords: hepatocellular carcinoma, trends, surgery, liver resection, efficacy

Posted Date: May 8th, 2020

DOI: https://doi.org/10.21203/rs.3.rs-26025/v1

License: (c) (1) This work is licensed under a Creative Commons Attribution 4.0 International License. Read Full License 


\section{Abstract \\ Background}

Surgery for the treatment of hepatocellular carcinoma (HCC) is limited. Recently, the possibility was advanced that surgical approach could be applied in HCC patients more widely. To address this issue, the trends in the use of surgery (including liver resection and ablation et, al) and liver resection for the treatment of HCC with time was analyzed. Additionally, whether patients gain a better survival benefit from surgery and liver resection than other treatments was evaluated.

\section{Methods}

Data from SEER registries was used to analyze the trends in the use surgery and liver resection for HCC and the survival benefits of these procedures. The study included patients between the ages of 35 and 84 years diagnosed as HCC between 1998 and $2015(n=80499)$. Propensity score matching (PSM) analysis was used to reduce selection bias.

\section{Results}

From 1998 to 2015, the rate of surgery for HCC increased in all patients $(P=0.016)$ and in the localized group $(P<0.001)$, but decrease in the regional and distant groups $(P<0.001)$. Liver resection rate in the localized, regional, distant, and unknown/unstaged groups declined $(P<0.001, P=0.004, P=0.014$, and $P=0.007$, respectively). Surgery and liver resection rates in the localized group and its subgroups of localized group were reduced (all $P<0.05$ ). The median overall survival (mOS) of patients undergoing surgery was longer than patients with non-surgery. Similar survival results were obtained in the analysis of the subgroups. The liver resection group had the longest mOS in all patients and in the localized (and it's subgroups) and regional groups.

\section{Conclusion}

Although surgery rate in HCC patients increased slightly with time, liver resection rate in the localized group decreased. Surgery might be used more widely in the treatment of patients with hepatocellular carcinoma.

\section{Introduction}

The incidence of hepatocellular carcinoma (HCC) becomes more frequent worldwide, with a $75 \%$ increase in the newly diagnosed cases from 1990 to 2015. It has been predicted that by 2030, HCC may become the third leading cause of cancer-related deaths in the USA[1]. The recommendations for the first-line treatment of early HCC include liver resection, transplantation or ablation. The first-line therapy for 
intermediate stages of HCC is transarterial chemoembolization (TACE), which can improve two-year survival outcomes. In advanced HCC with the tumor invading blood vessels and metastasizing to regional lymph nodes or distant organs, molecular-targeted drugs (sorafenib or lenvatinib) are recommended as the treatment of choice, which can extend the survival of the patients by up to 4 months[1, 2].

The decision to treat the patient surgically or by chemotherapy is based on tumor staging, and patient's liver function and physical condition. The most common criteria used worldwide for HCC staging are defined by Barcelona Clinic Liver Cancer (BCLC) staging[3]. Previous studies have shown showed that the survival of patients with a single tumor larger than $5 \mathrm{~cm}$ can be extended by liver resection[4,5]. However, whether patients with a single tumor larger than $5 \mathrm{~cm}$ should be characterized as BCLC stage $B$ is still a matter of controversy[6].

TACE is recommended as the first-line treatment for intermediate HCC and new embolic materials for this method, such as drug-eluting beads, have been developed. The drug-eluting beads may reduce complications of the TACE and prolong the progress-free survival but not overall survival $(O S)[7,8]$. However, some studies have documented that patients with intermediate HCC may have better survival after liver resection than TACE[9-11]. A prospective randomized controlled trial (RCT) showed that the 1-, 2-, and 3-year OS rates of patients with resectable multiple HCC outside of Milan Criteria who received liver resection were higher than that those of patients treated with TACE $(P<0.001)$ [9]. Another metaanalysis indicated that patients with intermediate-advanced HCC (BCLC B/C) who were treated by liver resection experienced greater survival benefit than those who received TACE therapy. In fact, all patients in the liver resection group had longer OS than patients in the TACE group $(P<0.0001)$ [12]. However, these studies had certain limitations. An insufficient number of patients was included in both investigations, and the meta-analysis included one RCT only, which might have led to a low level of evidence. The surgery and liver resection rate of patients is still unclear.

In view of these uncertainties, the present population-based study aimed at the analysis of the trends of surgery (including liver resection and tumor destruction) and liver resection, and to identify the optimal type of treatment for patients with different HCC stages.

\section{Methods}

\section{Study Cohort}

Using SEER 18 registries database, patients, 35-84 years old, diagnosed with HCC (International Classification of Diseases for Oncology, Third Edition (ICD-0-3), histology code 8170-8175, site code C220 (liver)) between 1998 and 2015 were included. The patients for which the information on whether they received surgical treatment was not available, were excluded. Finally, 78053 patients were included in the study: 18878 of them were treated surgically, and 59175 non-surgically. 
For the analysis of survival, patients with survival months code 0 (contact lost after diagnosis) and 9999 (unknown length of survival month) were excluded, leaving 66887 patients in this part of the study. After PSM, a total of 31120 patients were included into survival analysis. Among them, 15560 patients received surgery treatment and 15560 patients received non-surgery treatment. The baseline characteristics of patients before PSM and after PSM in the two group were compared (Table 1). 
Table 1

Characteristics of patients before PSM and after PSM.

\section{Characteristics}

\begin{tabular}{|c|c|c|c|c|c|c|}
\hline & $\begin{array}{l}\text { Surgery } \\
\text { (18563) } \\
\text { before }\end{array}$ & $\begin{array}{l}\text { Non- } \\
\text { surgery } \\
(48324)\end{array}$ & $P$ & $\begin{array}{l}\text { Surgery } \\
(15560) \\
\text { after PSM }\end{array}$ & $\begin{array}{l}\text { Non- } \\
\text { surgery } \\
(15560)\end{array}$ & $P$ \\
\hline Gender & & & $\begin{array}{l}< \\
0.001\end{array}$ & & & 0.668 \\
\hline Male & 13858 & 37542 & & 11899 & 11931 & \\
\hline Female & 4705 & 10782 & & 3661 & 3629 & \\
\hline Ethnicity & & & & & & 0.882 \\
\hline White & 12342 & 32917 & $<0.001$ & 10742 & 10726 & \\
\hline Black & 2001 & 6750 & & 1613 & 1597 & \\
\hline other & 4220 & 8657 & & 3205 & 3237 & \\
\hline Age of diagnosis & & & $<.001$ & & & 0.862 \\
\hline $35-44$ & 623 & 1155 & & 298 & 319 & \\
\hline $45-54$ & 3650 & 8721 & & 2812 & 2817 & \\
\hline $55-64$ & 7246 & 17186 & & 6034 & 6018 & \\
\hline$\geq 65$ & 7044 & 21262 & & 6416 & 6406 & \\
\hline Year of diagnosis & & & $\begin{array}{l}< \\
0.001\end{array}$ & & & 0.968 \\
\hline 1998-2001 & 1485 & 5120 & & 1114 & 1134 & \\
\hline $2002-2005$ & 3611 & 7857 & & 2639 & 2637 & \\
\hline $2006-2009$ & 4820 & 11216 & & 3818 & 3830 & \\
\hline 2010-2015 & 8647 & 24131 & & 7989 & 7959 & \\
\hline Tumor status & & & $\begin{array}{l}< \\
0.001\end{array}$ & & & 0.988 \\
\hline Localized & 14071 & 20123 & & 11497 & 11473 & \\
\hline Regional & 3480 & 14604 & & 3169 & 3194 & \\
\hline Distant & 534 & 8169 & & 480 & 478 & \\
\hline Unknown/Unstaged & 478 & 5428 & & 414 & 415 & \\
\hline
\end{tabular}




\begin{tabular}{|c|c|c|c|c|c|c|}
\hline Characteristics & Before & & & After $m$ & & \\
\hline Tumor size & & & $\begin{array}{l}< \\
0.001\end{array}$ & & & 0.998 \\
\hline$\leq 3 \mathrm{~cm}$ & 7839 & 9149 & & 6214 & 6215 & \\
\hline $3-5 \mathrm{~cm}$ & 4827 & 9097 & & 4168 & 4181 & \\
\hline $5-7 \mathrm{~cm}$ & 2006 & 6105 & & 1758 & 1747 & \\
\hline $7-9 \mathrm{~cm}$ & 944 & 4075 & & 814 & 798 & \\
\hline $9-11 \mathrm{~cm}$ & 568 & 2886 & & 467 & 460 & \\
\hline$>11 \mathrm{~cm}$ & 1160 & 4512 & & 988 & 1007 & \\
\hline Unknown & 1219 & 12500 & & 1151 & 1152 & \\
\hline Tumor numbers & & & $\begin{array}{l}< \\
0.001\end{array}$ & & & 0.985 \\
\hline 1 & 14932 & 41488 & & 13111 & 13125 & \\
\hline 2 & 2971 & 5778 & & 2138 & 2133 & \\
\hline 3 & 516 & 874 & & 260 & 252 & \\
\hline$>3$ & 144 & 184 & & 51 & 50 & \\
\hline Marital status & & & $\begin{array}{l}<.001 \\
0.0\end{array}$ & & & 0.910 \\
\hline Married & 11254 & 24402 & & 9116 & 9097 & \\
\hline Single & 6592 & 21618 & & 5929 & 5958 & \\
\hline Other & 717 & 2304 & & 515 & 505 & \\
\hline
\end{tabular}

To determine whether patients could gain an additional survival benefit from liver resection, the patients in localized group were divided into three groups (stage A-C) based on the BCLC stage A and B. Stage A included patients with a single tumor size smaller than $5 \mathrm{~cm}$ or 2-3 tumors with none larger than $3 \mathrm{~cm}$. Stage B included patients with a single tumor larger than $5 \mathrm{~cm}, 2-3$ tumors of which at least one was larger than $3 \mathrm{~cm}$, or more than 3 tumors regardless of their size. Stage $C$ included patients with a single tumor larger than $5 \mathrm{~cm}$. For survival analysis of patients in the stage $\mathrm{C}$ group, the group was further divided into four groups: group 1 with tumor size 5-7 cm ( $n=712)$, group 2 with tumor size 7-9 $\mathrm{cm}(\mathrm{n}=$ 336), group 3 with tumor size $9-11 \mathrm{~cm}(n=201)$, and group 4 with tumor size larger than $11 \mathrm{~cm}(n=390)$.

\section{Statistical analysis}

The patients' information was extracted from the SEER database using the SEER ${ }^{*}$ Stat software (version 8.3.5). Temporal trend of the rates of surgery and liver resection for the treatment of HCC was estimated 
using Cochran-Armitage test[13]. mOS was determined using Kaplan-Meier survival curves[14]. The prognostic factors for all patients and the liver resection group were assessed by Cox proportional hazards models[15].

The characteristics of gender, ethnicity, age of diagnosis, year of diagnosis, tumor status, tumor size, tumor numbers and marital status were included into PSM analysis. The optimal caliper was set as 0.00001 and 11560 pairs of were matched by 1:1 nearest neighbor approach. All statistical tests were two-sided, and the a level of $P<0.05$ was considered statistically significant. SPSS v24.0 (IBM, Chicago, IL, USA) and SAS 9.4 statistical software (SAS Institute, Cary, NC, USA) were used to perform all statistical analyses.

\section{Results}

\section{Trends of surgery and liver resection on HCC}

The number of patients and patients undergoing surgery increased with time from 1998 to 2015. However, the number of patients undergoing liver resection remained essentially constant (Additional File Fig. 1). The trends of surgery rate increased in all patients $(P=0.016)$, and patients with localized tumor $(P<0.001)$ increased but declined in the regional $(P<0.001)$ and the distant group $(P<0.001)$. The trends of surgery rate did not change with time in the unknown group $(P=0.360)$ (Fig. 1A). For liver resection, the frequencies and trends in localized $(P<0.001)$, regional $(P=0.004)$, distant $(P=0.014)$, and unknown groups $(P=0.007)$ declined with time (Fig. 1B). In the localized group, for stage $\mathrm{A}$, stage $\mathrm{B}$, and stage $\mathrm{C}$, the frequencies and trends of surgery and liver resection declined with time $(P<0.001$ for stage $A, B$ and C) (Fig. 2A-2B).

\section{Median Overall Survival (mOS) in all patients and the subgroups}

After PSM, the mOS of patients in the liver resection group (71 months, $95 \% \mathrm{Cl}: 67.4,74.6)$ was longer than in the other groups (surgery group ( 47 months, $95 \% \mathrm{Cl} ; 45.5,48.5)$, non-surgery group $(15$ months, $95 \% \mathrm{Cl}$ : 14.6,15.4), and all patients ( 26 months, $95 \% \mathrm{Cl}: 25.4,26.6), P<0.001)$ (Additional File Fig. 2). The mOS of patients in localized group who with liver resection $(85$ months, $95 \% \mathrm{Cl}: 80,90)$ was longer than patients with surgery (56 months, $95 \% \mathrm{Cl}$ : 53.9,8.1) and non-surgery (19 months, $95 \% \mathrm{Cl}: 18.4,19.6, \mathrm{P}<0.001$ ) (Fig. 3A). Similar results were presented in regional, distant and unknown stage groups. In reginal group, the mOS of patients with liver resection (43 months, $95 \% \mathrm{Cl}: 38.9,47.1)$ was longer than patients with surgery (29 months, $95 \% \mathrm{Cl}: 27,31)$ and non-surgery (9 months, 95\% Cl: 8.4,9.6, P<0.001) (Fig. 3B). In distant group, the mOS of patients with liver resection (13 months, $95 \% \mathrm{Cl}: 8.5,17.5)$ was longer than patients with surgery (10 months, $95 \% \mathrm{Cl}: 8.5,11.5)$ and non-surgery (3 months, $95 \% \mathrm{Cl}: 4.7,7.3, \mathrm{P}<0.001)$ (Fig. 3C). In the subgroups analysis, the patients in the stage A group who with liver resection (115 months, 95\% Cl: 105,125) had better survival than patients with surgery (65 months, 95\% Cl: 61.9,68.1) and non-surgery (23 months, 22.2,23.8, $\mathrm{P}<0.001$ ) (Fig. 4A). In stage $\mathrm{B}$ group, patients with liver resection (54 months, $95 \% \mathrm{Cl}: 49.6,58.4)$ had also better survival than patients with surgery $(42$ months, $95 \% \mathrm{Cl}$ : 
39.7,44.3) and non-surgery (10 months, $95 \% \mathrm{Cl}: 9.4,10.6, \mathrm{P}<0.001)$ (Fig. 4B).In stage $\mathrm{C}$ group, the mOS of patients with liver resection ( 51 months, $95 \% \mathrm{Cl}$ : 46.2,55.8) was longer than patients with surgery (39 months, 95\% Cl: 36,42) and non-surgery (9 months, 95\% Cl: 8.4,9.6, $\mathrm{P}<0.001)$ (Fig. 4C). To further evaluate the effect of surgery and liver resection in patients with tumor size larger than $5 \mathrm{~cm}$, the stage $C$ was divided into four groups: group 1 (tumor size 5-7cm), group $2(7-9 \mathrm{~cm})$, group $3(9-11 \mathrm{~cm})$ and group 4 $(>11 \mathrm{~cm}$.). The survival curve for the stage $\mathrm{C}$ group showed that the survival of patients with liver resection was longer in group 1 (61 months, 95\% Cl:51.9,70.1) than in group 2 (46months, 95\%Cl:32.8,59.2), group 3 (41 months, 95\%Cl:29.5,52.5), and group 4 (38months, 95\%Cl:31.5,44.5) $(P<$ 0.001) (Additional File Fig. 3).

\section{Predictors of OS in all patients and the liver resection group}

Cox proportional hazards models were used to identify independent predictors for OS in all patients $(n=$ $31120)$ who received surgery $(n=15560)$ or non-surgical treatment $(n=15560)$ after PSM. The female patients were more likely to survive longer (Hazard Ratio: $0.923,95 \% \mathrm{Cl}: 0.893,0.953 P<0.001$ ). The black patients were more likely to have the worst survival (HR:1.057, 95\%Cl: $1.011,1.106, P=0.015)$ than white patients and patients of other races. The younger patients had longer survival time (age 45-54 years: HR: 1.213, 95\%Cl: 1.092,1.347, $P=0.001 ; 55-64$ years: HR:1.307, 95\%Cl: 1.180,1.449, $P<0.001$; age $>65$ years: HR:1.652, 95\%Cl: $1.492,1.831, P<0.001)$ and patients with early diagnosis of HCC might had worse survival (diagnosis period 2002-2005, HR: 0.935, 95\%Cl: 0.887,0.986, $P=0.012 ; 2010-2015$, HR:0.800, 95\%Cl: 0.760,0.842, $P<0.001 ; 2010-2015$ : HR:0.674, 95\%Cl: 0.641,0.709, $P<0.001)$. A similar result was obtained for patients with larger tumor size. Patients undergoing surgery experienced better survival than non-surgically treated patients (non-surgery: HR: $2.544,95 \% \mathrm{Cl}: 2.474,2.616, P<0.001$ ). Married patients had better survival than single patients (single: HR:1.200, 95\% Cl: 1.166,1.235, $P<0.001$ ). However, patients with severaltumors had longer survival (two tumors: HR: $0.915,95 \% \mathrm{Cl}: 0.879,0.951, P<$ 0.001; three tumors: HR:0.894, 95\%Cl:0.804,0.994, $P=0.038$ ) (Table 2). 
Table 2

Multivariate regression analysis for overall survival of all patients

\begin{tabular}{|c|c|c|c|}
\hline Characteristics & No (\%) & Multivariate & \\
\hline & $31120(100)$ & $\mathrm{HR}(95 \% \mathrm{Cl})$ & $P$ \\
\hline \multicolumn{4}{|l|}{ Gender } \\
\hline Male & $23830(76.6)$ & Reference & \\
\hline Female & $7290(23.4)$ & $0.923(0.893,0.953)$ & $<0.001$ \\
\hline \multicolumn{4}{|l|}{ Ethnicity } \\
\hline White & $21468(69)$ & Reference & \\
\hline Black & $3210(10.3)$ & $1.057(1.011,1.106)$ & 0.015 \\
\hline other & $6442(20.7)$ & $0.783(0.756,0.811)$ & $<0.001$ \\
\hline \multicolumn{4}{|l|}{ Age of diagnosis } \\
\hline $35-44$ & $617(2)$ & Reference & \\
\hline $45-54$ & $5629(18.1)$ & $1.213(1.092,1.347)$ & 0.001 \\
\hline $55-64$ & 12052 (38.7) & $1.307(1.180,1.449)$ & $<0.001$ \\
\hline$\geq 65$ & $12822(41.2)$ & $1.652(1.492,1.831)$ & $<0.001$ \\
\hline \multicolumn{4}{|l|}{ Year of diagnosis } \\
\hline 1998-2001 & $2248(7.2)$ & Reference & \\
\hline $2002-2005$ & $5276(17)$ & $0.935(0.887,0.986)$ & 0.012 \\
\hline $2006-2009$ & 7648 (24.6) & $0.800(0.760,0.842)$ & $<0.001$ \\
\hline 2010-2015 & $15948(51.2)$ & $0.674(0.641,0.709)$ & $<0.001$ \\
\hline \multicolumn{4}{|l|}{ Tumor status } \\
\hline Localized & $22970(73.8)$ & Reference & \\
\hline Regional & $6363(20.4)$ & $1.524(1.475,1.574)$ & $<0.001$ \\
\hline Distant & $958(3.1)$ & $2.556(2.383,2.741)$ & $<0.001$ \\
\hline Unknown/Unstaged & $829(2.7)$ & $1.236(1.133,1.349)$ & $<0.001$ \\
\hline \multicolumn{4}{|l|}{ Tumor size } \\
\hline$\leq 3 \mathrm{~cm}$ & 12429 (39.9) & Reference & \\
\hline $3-5 \mathrm{~cm}$ & $8349(26.8)$ & $1.375(1.328,1.424)$ & $<0.001$ \\
\hline
\end{tabular}




\begin{tabular}{|llll|}
\hline Characteristics & No $(\%)$ & Multivariate & \\
\hline $5-7 \mathrm{~cm}$ & $3505(11.3)$ & $1.680(1.606,1.757)$ & $<0.001$ \\
\hline $7-9 \mathrm{~cm}$ & $1612(5.2)$ & $1.842(1.734,1.956)$ & $<0.001$ \\
\hline $9-11 \mathrm{~cm}$ & $927(3)$ & $2.128(1.973,2.296)$ & $<0.001$ \\
\hline$>11 \mathrm{~cm}$ & $1995(6.4)$ & $2.351(2.226,2.484)$ & $<0.001$ \\
\hline Unknown & $2303(7.4)$ & $1.930(1.822,2.044)$ & $<0.001$ \\
\hline Tumor numbers & & & \\
\hline 1 & $26236(84.3)$ & Reference & \\
\hline 2 & $4271(13.7)$ & $0.915(0.879,0.951)$ & $<0.001$ \\
\hline 3 & $512(1.7)$ & $0.894(0.804,0.994)$ & 0.038 \\
\hline$>3$ & $101(0.3)$ & $0.996(0.787,1.261)$ & 0.974 \\
\hline Marital status & & & \\
\hline Married & $18213(58.5)$ & Reference & \\
\hline Single & $11887(38.2)$ & $1.200(1.166,1.235)$ & $<0.001$ \\
\hline Other & $1020(3.3)$ & $1.028(0.947,1.116)$ & 0.509 \\
\hline Surgery & & & \\
\hline Yes & $11560(50)$ & Reference & \\
\hline not & $15560(50)$ & $2.544(2.474,2.616)$ & $<0.001$ \\
\hline
\end{tabular}

In the localized group, patients with liver resection, the multivariate analysis yielded similar results: gender, ethnicity, age, year of diagnosis, tumor stage, tumor size and marital status affected the length of survival. However, the higher number of tumors was not did not improve OS in liver resection patients (Table 3). 
Table 3

Multivariate regression analysis for overall survival of patients in the localized group who with liver resection

\begin{tabular}{|c|c|c|c|}
\hline \multirow[t]{2}{*}{ Characteristic } & \multirow{2}{*}{$\begin{array}{l}\text { No (\%) } \\
8652(100)\end{array}$} & \multicolumn{2}{|l|}{ Multivariate } \\
\hline & & $\mathrm{HR}(95 \% \mathrm{Cl})$ & $P$ \\
\hline \multicolumn{4}{|l|}{ Gender } \\
\hline Male & $6568(75.9)$ & Reference & \\
\hline Female & $2084(24.1)$ & $0.847(0.776,0.924)$ & $<0.001$ \\
\hline \multicolumn{4}{|l|}{ Ethnicity } \\
\hline White & $5832(67.4)$ & Reference & \\
\hline Black & 907 (10.5) & $1.411(1.255,1.587)$ & $<0.001$ \\
\hline other & $1913(22.1)$ & $0.852(0.775,0.936)$ & 0.001 \\
\hline \multicolumn{4}{|c|}{ Age of diagnosis } \\
\hline $35-44$ & $217(2.5)$ & Reference & \\
\hline $45-54$ & 1675 (19.4) & $1.448(1.073,1.955)$ & 0.015 \\
\hline $55-64$ & $3320(38.3)$ & $1.682(1.252,2.258)$ & 0.001 \\
\hline$\geq 65$ & 3440 (39.8) & $2.530(1.886,3.393)$ & $<0.001$ \\
\hline \multicolumn{4}{|c|}{ Year of diagnosis } \\
\hline 1998-2001 & $722(8.3)$ & Reference & \\
\hline $2002-2005$ & $1490(17.2)$ & $0.809(0.715,0.916)$ & 0.001 \\
\hline $2006-2009$ & $2151(24.9)$ & $0.687(0.608,0.776)$ & $<0.001$ \\
\hline 2010-2015 & $4289(49.6)$ & $0.509(0.449,0.576)$ & $<0.001$ \\
\hline \multicolumn{4}{|l|}{ Tumor size } \\
\hline$\leq 3 \mathrm{~cm}$ & 3071 (35.4) & Reference & \\
\hline $3-5 \mathrm{~cm}$ & $2298(26.6)$ & $1.412(1.283,1.555)$ & $<0.001$ \\
\hline $5-7 \mathrm{~cm}$ & $1161(13.4)$ & $1.646(1.466,1.849)$ & $<0.001$ \\
\hline $7-9 \mathrm{~cm}$ & $587(6.8)$ & $1.911(1.652,2.210)$ & $<0.001$ \\
\hline $9-11 \mathrm{~cm}$ & $354(4.1)$ & $2.118(1.767,2.540)$ & $<0.001$ \\
\hline$>11 \mathrm{~cm}$ & $793(9.2)$ & $2.310(2.009,2.655)$ & $<0.001$ \\
\hline Unknown & $388(4.5)$ & $1.344(1.099,1.644)$ & 0.004 \\
\hline
\end{tabular}




\begin{tabular}{|lllll|}
\hline Characteristic & No (\%) & Multivariate & \\
\hline Tumor numbers & & & \\
\hline 1 & $7305(84.4)$ & Reference & \\
\hline 2 & $1181(13.7)$ & $1.011(0.913,1.120)$ & 0.830 & \\
3 & $137(1.6)$ & $1.101(0.850,1.426)$ & 0.464 & \\
$>3$ & $29(0.3)$ & $0.965(0.558,1.669)$ & 0.898 & \\
Marital status & & & & \\
Married & $5425(62.7)$ & Reference & & \\
\hline Single & $2976(34.4)$ & $1.294(1.196,1.399)$ & & 0.001 \\
\hline Other & $251(2.9)$ & $0.928(0.716,1.203)$ & & 0.574 \\
\hline
\end{tabular}

\section{Discussion}

The incidence of HCC in men and women increased from 2000 to 2013 and is predicted to increase until 2030[16]. The current investigation documented the number of HCC cases clearly increased from 1998 to 2015. The main finding was that the survival of HCC patients benefits more from surgery than nonsurgery treatment and that the liver resection might be the best choice for the treatment of all subgroups of HCC patients with localized tumor and regional tumor invasion at different periods (1998 to 2001, 2002 to 2005,2006 to 2009 and 2010 to 2015 ).

It has been previously shown that patients with single and small HCC who received radiofrequency ablation (RFA) had similar survival benefits from the therapy as patients undergoing liver resection[1720]. With the development of microwave ablation and cryoablation, the surgery is better tolerated by the patients. In the past, the radiotherapy was not suitable for HCC treatment because the radiation could damage the normal liver tissue and vital organs located in the vicinity of the liver[21, 22]. However, patients with early HCC treated with stereotactic body radiation therapy (SBRT) which allows precise targeting of the tumor have similar 1- and 2-years OS comparable to that achieved with RFA[23, 24].

Since 1999, BCLC criteria have been used as a recommended guide for HCC treatment[25]. Liver resection was advised for the treatment of HCC patients with BCLC stage A, who had good liver function and good physical condition. This recommendation limited the application of liver resection in HCC treatment. For BCLC stage B patients, TACE was recommended as the first-line treatment. HCC patients with BCLC stage $B$ who received TACE treatment had shorter mOS (16 to 42 months) than patients undergoing liver resection (23 to 70 months; $P<0.05$ ) [10, 26-29]. The major disadvantage of TACE is the difficulty of achieving complete embolization of the arteries, which, if successful, would lead to ischemia and hypoxia of the tumor microenvironment. The hypoxic tumor microenvironment can trigger the generation of 
several cytokines which prevent hypoxia-inducible factor a decreasing, by tumor cells, promoting the growth of tumor microvessels which facilitate tumor growth and metastasis[30, 31].

Alternatively, the tumor can be removed completely by liver resection, reducing tumor recurrence and metastasis. In the present analysis, patients with localized HCC were divided into three groups (stage A, stage $B$, and stage $C$ ) according to size and number of tumors. The mOS of patients with HCC stages A, $B$, and $C$ undergoing liver resection group had the longest mOS. The classification of localized group was based on BCLC stage but did not include the liver function and physical condition of the patients. However, the analysis of all patients who were recommended to be treated surgically but did not consent indicated that the mOS of these patients ( 21 months, $95 \% \mathrm{Cl}: 18.1,23.9)$ was lower than of patients undergoing surgery (47 months, $95 \% \mathrm{Cl}: 45.45,48.5)$ or liver resection $(71$ months, $95 \% \mathrm{Cl}: 67.4,74.6)$. This difference indicates that patients with adequate liver function and physical condition can get survival benefits from surgery or liver resection.

It was suggested that patients with a single tumor larger than $5 \mathrm{~cm}$ should be classified as BCLC stage A and receive a better survival benefit from liver resection[32]. However, in the current analysis, the patients in the localized group with a single tumor larger than $5 \mathrm{~cm}$ were divided into four subgroups (group 1: 5$7 \mathrm{~cm}$; group 2: 7-9 cm; group 3: 9-11 cm; group 4: >11 cm) and the efficacy of liver resection treatment was determined in each subgroup. Patients with a single tumor sized $5-7 \mathrm{~cm}$ had longer survival than patients with a single tumor larger than $11 \mathrm{~cm}$. Although with increasing tumor diameter the possibility of vascular invasion and metastasis becomes higher, many patients with a single tumor larger than $5 \mathrm{~cm}$ do not exhibit vascular invasion or metastasis. Thus, simply dividing these patients into one category may not be justified. However, thus far no RCT was performed for patients with single tumor larger than $5 \mathrm{~cm}$ that would focus on the effect of tumor size on the therapeutic efficacy of liver resection or other types of surgery, such as TACE. Therefore, the outcome of various treatments in patients with different tumor size was worth exploring by a large cohort study.

Multivariate analysis of all patients included in this study also demonstrated that surgical treatment resulted in better mOS of the patients than non-surgical therapies. In agreement with earlier publications, older patients, male patients, black patients, patients with larger tumor size, patients with tumor metastasis, single patients and patients with an early diagnosis of HCC had a worse prognosis. Several studies have shown that a higher number of tumors is associated with a worse prognosis of the HCC patients with radical treatment[33-35]. However, the current work documented that the presence of multiple tumors was increased mOS of the patients. In multivariate analysis, we included patients with regional tumor invasion $(n=6363)$, distant metastasis $(n=958)$ and unknown stage patients $(n=829)$ who might influence the prognostic factors of all patients. So, we did multivariate analysis of OS for patients with liver resection in localized group and found that the patients with more tumor numbers might influent the prognosis of patients compared with patients with single tumor.

Although this study provided encouraging results for patients with treated surgically, in particular by liver resection, the surgery rate did not increase significantly with time, and the liver resection rate decreased in 
all patients and subgroups. These trends may be explained by the emergence of new surgical techniques. The recommendation by the BCLC criteria that patients with BCLC stage A and good liver function and physical condition should be treated by liver resection might be another reason for the decline in the treatment of HCC by liver resection. However, the results of the present analysis support the notion that patients can obtain a better survival benefit from liver resection than from other types of surgery. This conclusion was valid in all patients, in the localized group and its subgroups, and in the regional group. Patients with regional vascular and lymph invasion were considered to have advanced disease and to require a molecularly targeted drug treatment.

Recently, the concept of tumor oligometastasis was advanced and numerous studies have shown that patients with oligometastases who underwent the resection or radiotherapy of the primary tumor and metastatic lymph nodes could get better survival benefits than non-surgically treated patients[36, 37]. However, there was no one RCT focused on comparing the efficacy of liver resection with other treatments in patients with $\mathrm{HCC}$ oligometastases. The results obtained here indicate that patients with invasion of regional vascular and lymph nodes have longer survival in comparison with patients undergoing other treatments. Although the present work did not consider the liver function and physical condition of patients, the patients that were qualified for surgery but declined most likely had good liver function and physical condition. The results in this group of patients support the notion that surgery is a better treatment choice for HCC patients.

At present, the laparoscopic technique is more widely used in the treatment of HCC, because it reduces injury and increases patient tolerance to surgery. Therefore, expanding the application of liver resection in HCC patients beyond BCLC stage A and Child-Turcotte-Pugh class A or B and ECOG score 0 might be worth considering and exploring in-depth. BCLC guidelines recommend that BCLC stage B HCC patients with Child-Turcotte-Pugh class A or B and ECOG score 0 should receive TACE treatment. The use of drugeluting beads TACE (DEB-TACE) in HCC patients does not prolong the survival of patients in comparison with conventional TACE, but it can reduce the adverse events of the treatment. Therefore, the appropriateness of the DEB-TACE treatment for HCC patients with Child-Turcotte-Pugh class $\mathrm{C}$ is worth exploring.

The retrospective design of the present study constitutes its limitation since it might have led to a selection bias. However, the analysis was based on a large number of patients, which could increase the reliability of the results. The efficacy of liver resection was compared only with other treatments, but comparisons with specific treatments were not performed. While this approach might not provide strong proof that liver resection is the best treatment for patients with a localized tumor or regional metastases, the evidence was obtained that patients can receive a better survival benefit from surgery, and liver resection might be the best treatment choice. This study did not answer the question of whether patients with poor liver function and physical status should be treated surgically, but from the side, these patients could get better survival after undergoing surgery. The conclusions reached here need to be confirmed by a large prospective cohort study. 


\section{Conclusions}

In conclusion, this study provided a comprehensive analysis of the trends in the rate of surgery and liver resection for the treatment of HCC. Moreover, the efficacy of surgery was compared with the efficacy of non-surgery and liver resection in patients with different stages of HCC. The results indicated that surgery (especially for liver resection) might be used more widely in the treatment of HCC.

\section{Declarations}

Ethics approval and consent to participate: The research do not need to be reviewed by the ethics committee because the data were from SEER database and the written informed consent was exempted. However, the data used in the research was permitted by the SEER database management department.

Consent to publish: Not applicable.

Available of data and materials: The data could be found in SEER database (https://seer.cancer.gov/data/).

Competing interests: The authors declare that they have no competing interests.

Funding: This study was supported by National Natural Science Foundation of China (No. 81873919). The funders had no role in the study design, data collection, data analysis, decision to publish.

\section{Authors' contributions:}

ZCS, FY conceived the study, analyzed the data. CL and CS performed the data collection and conducted the statistical analysis. CL, CS and ST writed the manuscript. All authors read and approved the final manuscript.

Acknowledgement: Not applicable.

Authors' information: $\mathrm{CL}, \mathrm{MD}^{\# 1,2,3} ; \mathrm{CS}, \mathrm{MD}^{\# 1,2} ; \mathrm{ST}, \mathrm{MD}^{1,2,3} ; \mathrm{YF}, \mathrm{MD}, \mathrm{PhD}^{\star 1,2} ; \mathrm{ZCS}, \mathrm{MD}, \mathrm{PhD}^{\star 1,2,3}$

${ }^{1}$ From the department of Radiology, Union Hospital, Tongji Medical College, Huazhong University of Science and Technology, Wuhan, 430022, China;

${ }^{2}$ From Hubei Province Key Laboratory of Molecular Imaging, Wuhan, 430022, China.

${ }^{3}$ From the department of interventional radiology, Union Hospital, Tongji Medical College, Huazhong University of Science and Technology, Wuhan, 430022, China.

\section{References}


1. EASL Clinical. Practice Guidelines: Management of hepatocellular carcinoma. J Hepatol. 2018;69(1):182-236.

2. Bruix J, Sherman M. Management of hepatocellular carcinoma: an update. Hepatology. 2011;53(3):1020-2.

3. Forner A, Reig M, Bruix J. Hepatocellular carcinoma. Lancet. 2018;391(10127):1301-14.

4. Cho YB, Lee KU, Lee HW, Cho EH, Yang SH, Cho JY, Yi NJ, Suh KS. Outcomes of hepatic resection for a single large hepatocellular carcinoma. World journal of surgery. 2007;31(4):795-801.

5. Ai JH, Li JW, Chen J, Bie P, Wang SG, Zheng SG. Feasibility and safety of laparoscopic liver resection for hepatocellular carcinoma with a tumor size of 5-10 cm. PLoS One. 2013;8(8):e72328.

6. Zhong JH, Lu SD, Wang YY, Ma L, Li LQ. Intermediate-stage HCC-upfront resection can be feasible. Nature reviews Clinical oncology 2015, 12(5).

7. Lammer J, Malagari K, Vogl T, Pilleul F, Denys A, Watkinson A, Pitton M, Sergent G, Pfammatter T, Terraz S, et al. Prospective randomized study of doxorubicin-eluting-bead embolization in the treatment of hepatocellular carcinoma: results of the PRECISION V study. Cardiovasc Intervent Radiol. 2010;33(1):41-52.

8. Malagari K, Pomoni M, Kelekis A, Pomoni A, Dourakis S, Spyridopoulos T, Moschouris H, Emmanouil E, Rizos S, Kelekis D. Prospective randomized comparison of chemoembolization with doxorubicineluting beads and bland embolization with BeadBlock for hepatocellular carcinoma. Cardiovasc Intervent Radiol. 2010;33(3):541-51.

9. Yin L, Li H, Li AJ, Lau WY, Pan ZY, Lai EC, Wu MC, Zhou WP. Partial hepatectomy vs. transcatheter arterial chemoembolization for resectable multiple hepatocellular carcinoma beyond Milan Criteria: a RCT. J Hepatol. 2014;61(1):82-8.

10. Tada T, Kumada T, Toyoda H, Tsuji K, Hiraoka A, Itobayashi E, Nouso K, Kariyama K, Ishikawa T, Hirooka $\mathrm{M}$, et al. Role of hepatic resection in patients with intermediate-stage hepatocellular carcinoma: A multicenter study from Japan. Cancer Sci. 2017;108(7):1414-20.

11. Lee JM, Jang BK, Lee YJ, Choi WY, Choi SM, Chung WJ, Hwang JS, Kang KJ, Kim YH, Chauhan AK, et al. Survival outcomes of hepatic resection compared with transarterial chemoembolization or sorafenib for hepatocellular carcinoma with portal vein tumor thrombosis. Clinical molecular hepatology. 2016;22(1):160-7.

12. Hyun MH, Lee YS, Kim JH, Lee CU, Jung YK, Seo YS, Yim HJ, Yeon JE, Byun KS. Hepatic resection compared to chemoembolization in intermediate- to advanced-stage hepatocellular carcinoma: A meta-analysis of high-quality studies. Hepatology. 2018;68(3):977-93.

13. Buonaccorsi JP, Laake P, Veierod MB. On the power of the Cochran-Armitage test for trend in the presence of misclassification. Stat Methods Med Res. 2014;23(3):218-43.

14. van Walraven C, McAlister FA. Competing risk bias was common in Kaplan-Meier risk estimates published in prominent medical journals. J Clin Epidemiol. 2016;69:170-3 e178.

15. Staley JR, Jones E, Kaptoge S, Butterworth AS, Sweeting MJ, Wood AM, Howson JMM. A comparison of Cox and logistic regression for use in genome-wide association studies of cohort and case-cohort 
design. Eur J Hum Genet. 2017;25(7):854-62.

16. Petrick JL, Kelly SP, Altekruse SF, McGlynn KA, Rosenberg PS. Future of Hepatocellular Carcinoma Incidence in the United States Forecast Through 2030. J Clin Oncol. 2016;34(15):1787-94.

17. Chen MS, Li JQ, Zheng Y, Guo RP, Liang HH, Zhang YQ, Lin XJ, Lau WY. A prospective randomized trial comparing percutaneous local ablative therapy and partial hepatectomy for small hepatocellular carcinoma. Ann Surg. 2006;243(3):321-8.

18. Peng ZW, Lin XJ, Zhang YJ, Liang HH, Guo RP, Shi M, Chen MS. Radiofrequency ablation versus hepatic resection for the treatment of hepatocellular carcinomas $2 \mathrm{~cm}$ or smaller: a retrospective comparative study. Radiology. 2012;262(3):1022-33.

19. Pompili M, Saviano A, de Matthaeis N, Cucchetti A, Ardito F, Federico B, Brunello F, Pinna AD, Giorgio A, Giulini SM, et al. Long-term effectiveness of resection and radiofrequency ablation for single hepatocellular carcinoma $</=3 \mathrm{~cm}$. Results of a multicenter Italian survey. J Hepatol. 2013;59(1):8997.

20. Jiang YQ, Wang ZX, Deng YN, Yang Y, Wang GY, Chen GH. Efficacy of Hepatic Resection vs. Radiofrequency Ablation for Patients With Very-Early-Stage or Early-Stage Hepatocellular Carcinoma: A Population-Based Study With Stratification by Age and Tumor Size. Frontiers in oncology. 2019;9:113.

21. Ohri N, Dawson LA, Krishnan S, Seong J, Cheng JC, Sarin SK, Kinkhabwala M, Ahmed MM, Vikram B, Coleman CN, et al: Radiotherapy for Hepatocellular Carcinoma: New Indications and Directions for Future Study. Journal of the National Cancer Institute 2016, 108(9).

22. Lawrence TS, Ten Haken RK, Kessler ML, Robertson JM, Lyman JT, Lavigne ML, Brown MB, DuRoss DJ, Andrews JC, Ensminger WD, et al. The use of 3-D dose volume analysis to predict radiation hepatitis. Int J Radiat Oncol Biol Phys. 1992;23(4):781-8.

23. Wahl DR, Stenmark MH, Tao Y, Pollom EL, Caoili EM, Lawrence TS, Schipper MJ, Feng M. Outcomes After Stereotactic Body Radiotherapy or Radiofrequency Ablation for Hepatocellular Carcinoma. J Clin Oncol. 2016;34(5):452-9.

24. Seo YS, Kim MS, Yoo HJ, Jang WI, Paik EK, Han CJ, Lee BH. Radiofrequency ablation versus stereotactic body radiotherapy for small hepatocellular carcinoma: a Markov model-based analysis. Cancer medicine. 2016;5(11):3094-101.

25. Llovet JM, Bru C, Bruix J. Prognosis of hepatocellular carcinoma: the BCLC staging classification. Semin Liver Dis. 1999;19(3):329-38.

26. Kim JY, Sinn DH, Gwak GY, Choi GS, Saleh AM, Joh JW, Cho SK, Shin SW, Carriere KC, Ahn JH, et al. Transarterial chemoembolization versus resection for intermediate-stage (BCLC B) hepatocellular carcinoma. Clinical molecular hepatology. 2016;22(2):250-8.

27. Lin C-L, Lin C-K, Lin T-J, Lee H-C, Chen K-Y, Liao L-Y, Ting C-T, Wang C-K. Comparison of surgical resection and transarterial chemoembolization for patients with intermediate stage hepatocellular carcinoma. Journal of Cancer Research Practice. 2016;3(2):34-8. 
28. Luo J, Peng ZW, Guo RP, Zhang YQ, Li JQ, Chen MS, Shi M. Hepatic resection versus transarterial lipiodol chemoembolization as the initial treatment for large, multiple, and resectable hepatocellular carcinomas: a prospective nonrandomized analysis. Radiology. 2011;259(1):286-95.

29. Lin CT, Hsu KF, Chen TW, Yu JC, Chan DC, Yu CY, Hsieh TY, Fan HL, Kuo SM, Chung KP, et al. Comparing hepatic resection and transarterial chemoembolization for Barcelona Clinic Liver Cancer (BCLC) stage B hepatocellular carcinoma: change for treatment of choice? World journal of surgery. 2010;34(9):2155-61.

30. Zhang J, Zhang Q, Lou Y, Fu Q, Chen Q, Wei T, Yang J, Tang J, Wang J, Chen Y, et al. Hypoxiainducible factor-1 alpha/interleukin-1beta signaling enhances hepatoma epithelial-mesenchymal transition through macrophages in a hypoxic-inflammatory microenvironment. Hepatology. 2018;67(5):1872-89.

31. Dang CV, Semenza GL. Oncogenic alterations of metabolism. Trends Biochem Sci. 1999;24(2):6872.

32. Forner A, Gilabert M, Bruix J, Raoul JL. Treatment of intermediate-stage hepatocellular carcinoma. Nature reviews Clinical oncology. 2014;11(9):525-35.

33. Toyoda H, Kumada T, Kaneoka Y, Osaki Y, Kimura T, Arimoto A, Oka H, Yamazaki O, Manabe T, Urano $F$, et al. Prognostic value of pretreatment levels of tumor markers for hepatocellular carcinoma on survival after curative treatment of patients with HCC. J Hepatol. 2008;49(2):223-32.

34. Toyoda H, Kumada T, Tada T, Niinomi T, Ito T, Kaneoka Y, Maeda A. Prognostic significance of a combination of pre- and post-treatment tumor markers for hepatocellular carcinoma curatively treated with hepatectomy. J Hepatol. 2012;57(6):1251-7.

35. Xu XF, Xing H, Han J, Li ZL, Lau WY, Zhou YH, Gu WM, Wang H, Chen TH, Zeng YY, et al. Risk Factors, Patterns, and Outcomes of Late Recurrence After Liver Resection for Hepatocellular Carcinoma: A Multicenter Study From China. JAMA surgery. 2019;154(3):209-17.

36. Gomez DR, Tang C, Zhang J, Blumenschein GR Jr, Hernandez M, Lee JJ, Ye R, Palma DA, Louie AV, Camidge DR, et al. Local Consolidative Therapy Vs. Maintenance Therapy or Observation for Patients With Oligometastatic Non-Small-Cell Lung Cancer: Long-Term Results of a MultiInstitutional, Phase II, Randomized Study. J Clin Oncol. 2019;37(18):1558-65.

37. Palma DA, Olson R, Harrow S, Gaede S, Louie AV, Haasbeek C, Mulroy L, Lock M, Rodrigues GB, Yaremko BP, et al: Stereotactic ablative radiotherapy versus standard of care palliative treatment in patients with oligometastatic cancers (SABR-COMET): a randomised, phase 2, open-label trial. Lancet (London, England) 2019, 393(10185):2051-2058.

\section{Figures}



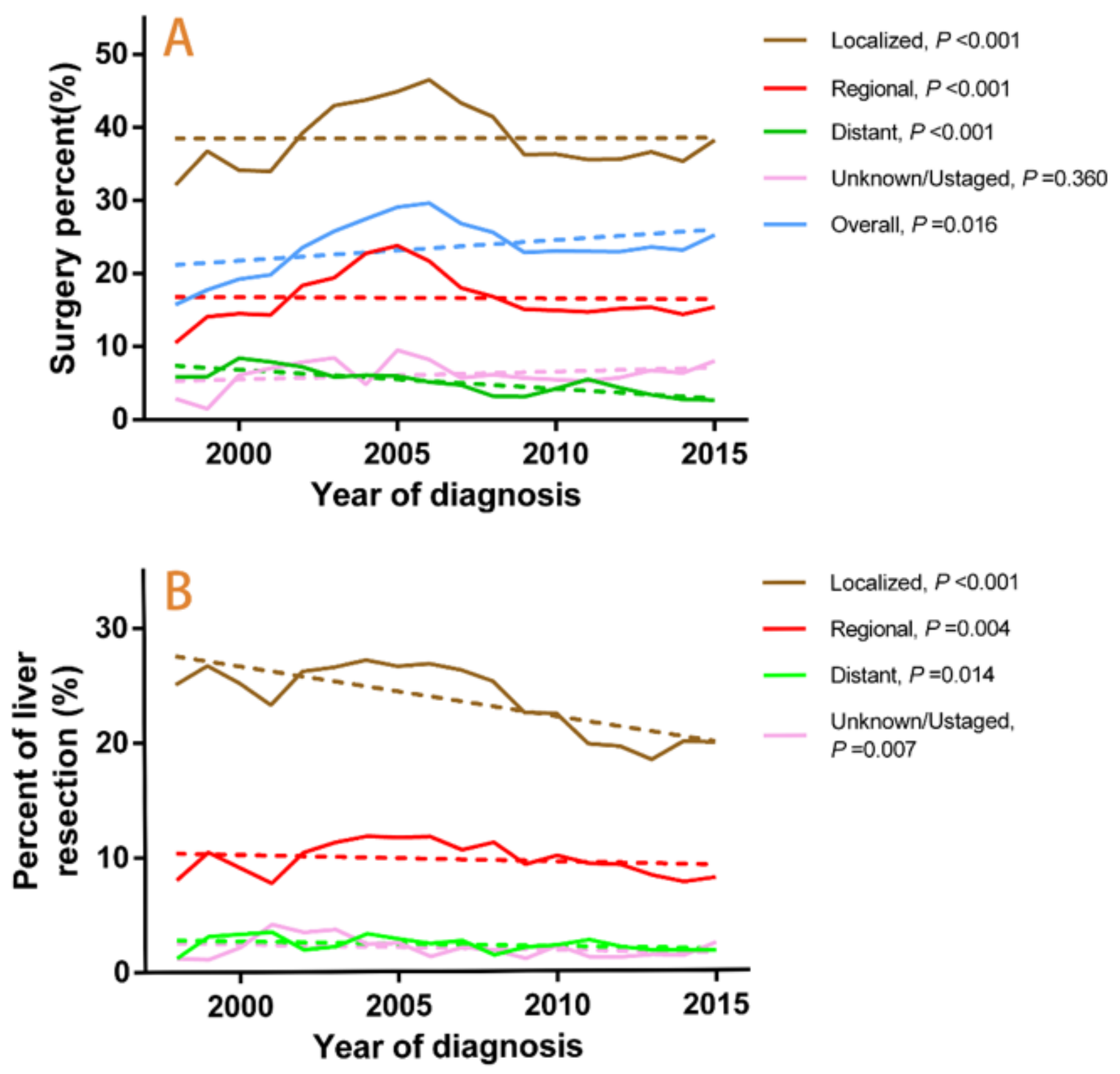

Figure 1

The trends of surgery rate (A) and liver resection rate (B) in localized group, regional group, distant group and unknown/unstaged group from 1998 to 2015. 

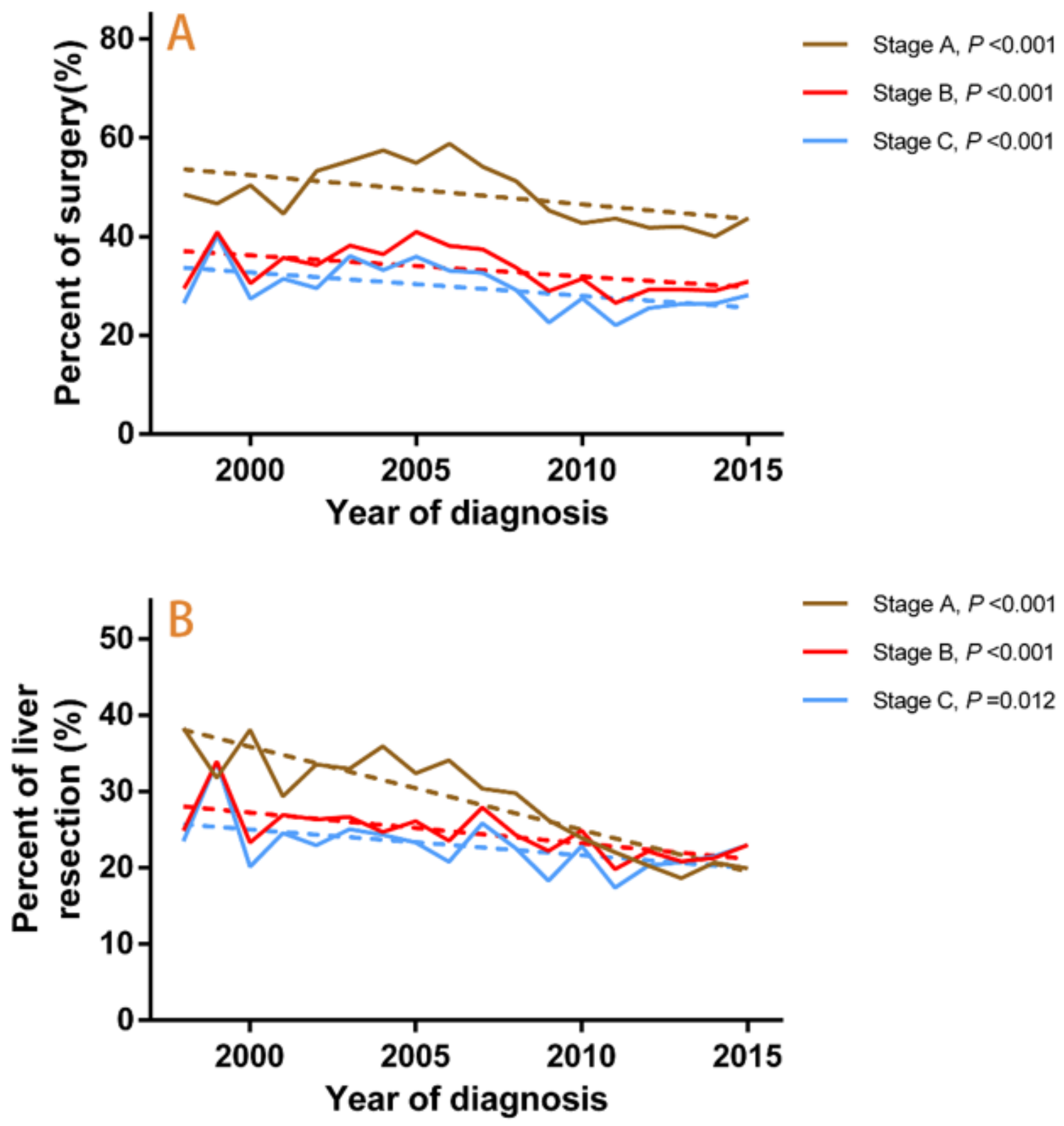

Figure 2

The localized group was divided into three group (stage A, B and C) according to the tumor size and numbers based on Barcelona Clinic Liver Cancer (BCLC) criteria. This figure presented that the trends of surgery rate $(A)$ and liver resection rate $(B)$ in stage $A$ group, stage $B$ group and stage $C$ group from 1998 to 2015. 

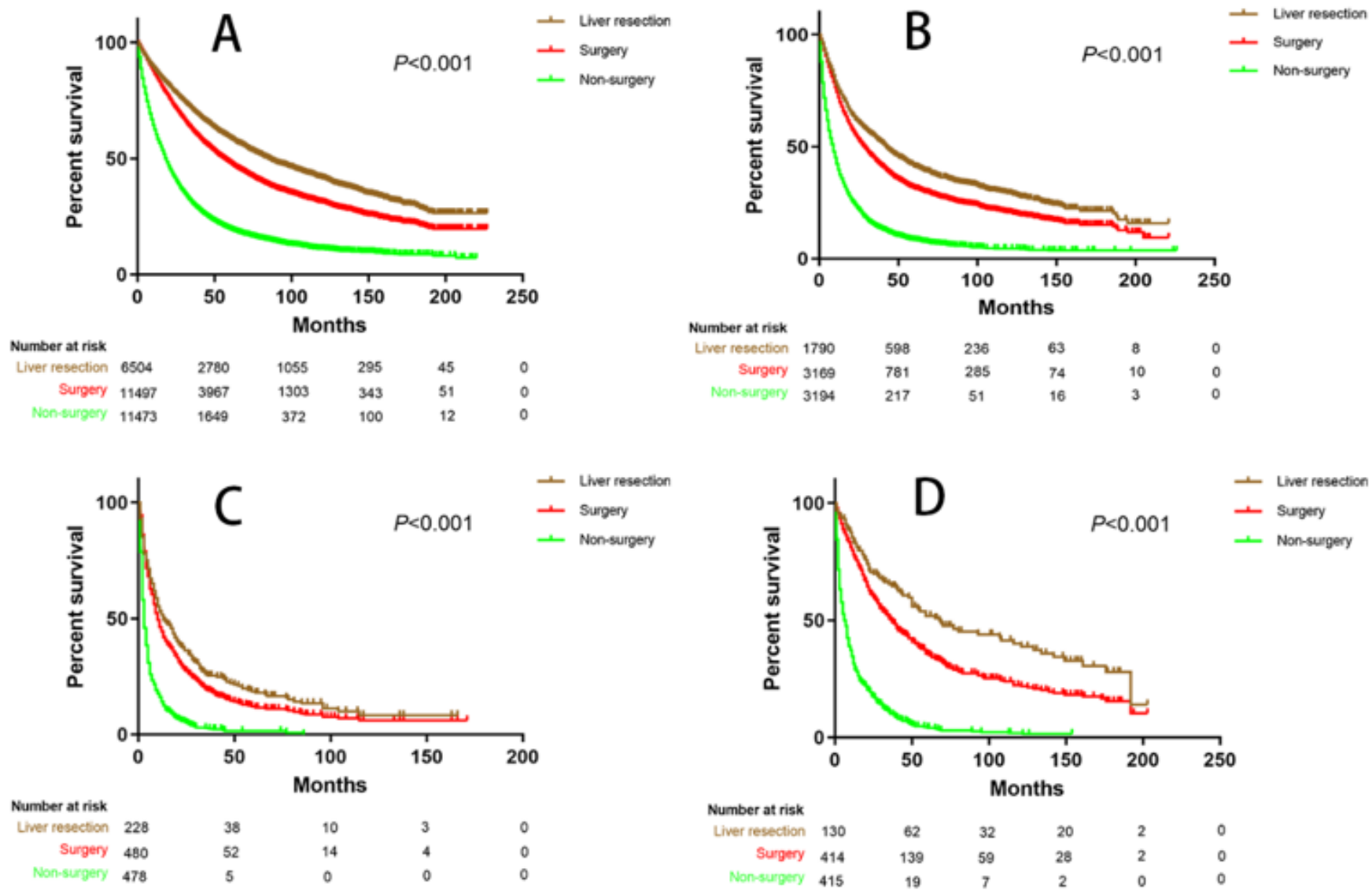

\section{Figure 3}

Cumulative survival of patients in localized group (A), regional group (B), distant group (C) and unknown/unstaged group (D) who received surgery or non-surgery or liver resection treatment. 


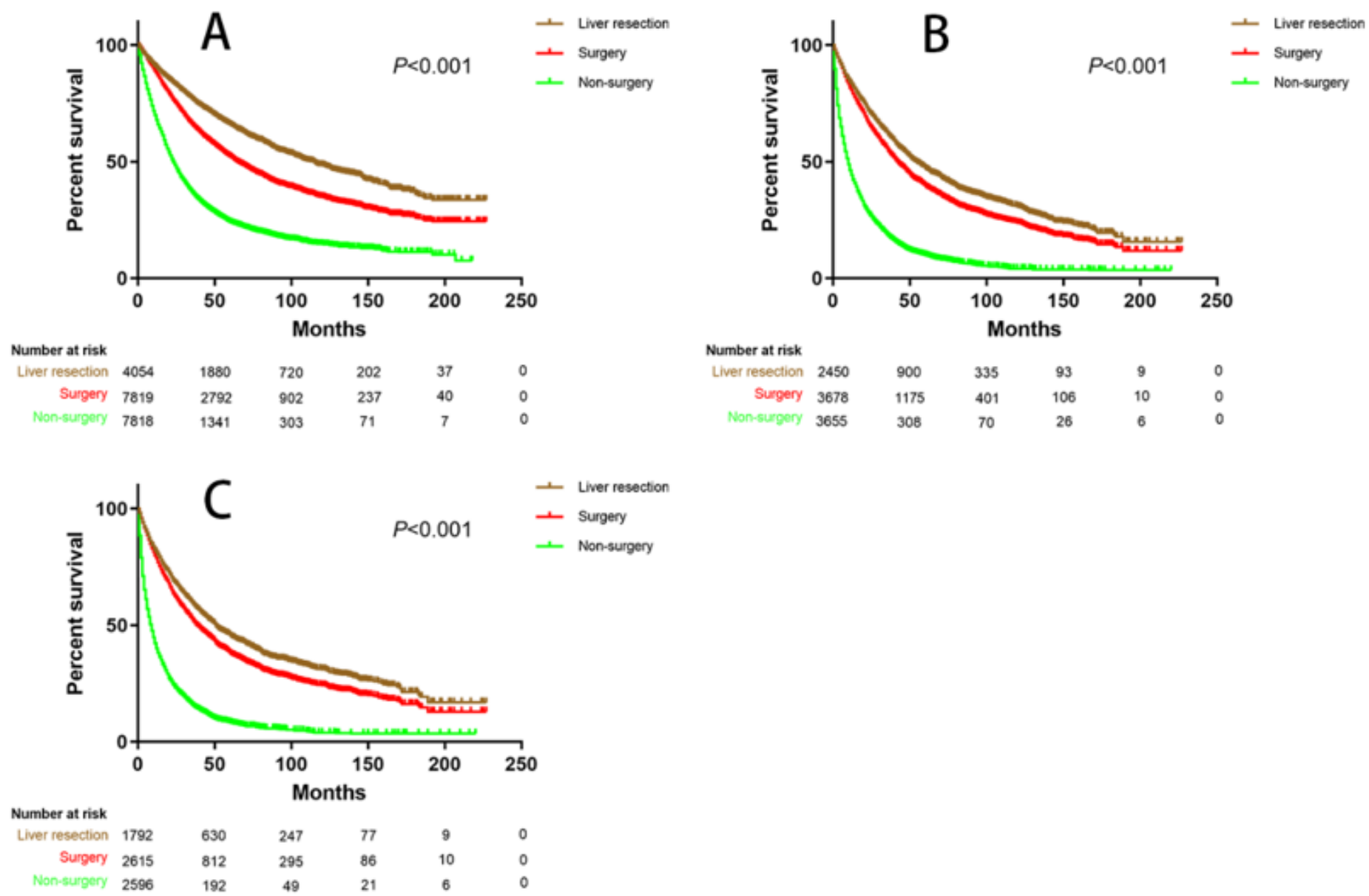

\section{Figure 4}

Cumulative survival of patients in localized subgroups: stage $A(A)$, stage $B(B)$ and stage $C(C)$ group who received surgery or non-surgery or liver resection treatment.

\section{Supplementary Files}

This is a list of supplementary files associated with this preprint. Click to download.

- AdditionalFileFigures.docx 